HORTSCIENCE 27(3):252-254. 1992.

\title{
PGI Isozyme Diversity and Its Genetic Control in Mango
}

Chemda Degani, Menashe Cohen, and Ruth El-Batsri

Institute of Horticulture, Agriculture Research Organization, The Volcani Center, Bet Dagan, 50250, Israel

\section{Shmuel Gazit}

Faculty of Agriculture, The Hebrew University of Jerusalem, Rehovot, Israel

Additional index words. Mangifera indica, phosphoglucose isomerase, allozymes

Abstract. Leaf phosphoglucose isomerase (PGI) isozymes from 139 cultivars and seedlings of mango (Mangifera indica $\mathbf{L}$.) were analyzed by starch gel electrophoresis. Six distinct banding patterns of PGI-2 consisting of single- and triple-banded phenotypes were detected. The genetic control of PGI-2 isozymes were inferred from segregating progenies of self-pollinated parent cultivars having triple-banded phenotypes. Comparison of the banding patterns of PGI-2 isozymes extracted from the pollen and the leaf of the same heterozygous cultivar demonstrates the allelism of the Pgi-2 locus.

Phosphoglucose isomerase (PGI: EC 5.3.1.9) is a glycolytic enzyme catalyzing the reversible isomerization of glucose-6phosphate and fructose-6-phosphate (Noltmann, 1972). In most plant species, PGI is

Received for publication 28 May 1991. Accepted for publication 9 Oct. 1991. Contribution from the Agricultural Research Organization, The Volcani Center, Bet Dagan, Israel. no. 3349-E, $1991 \mathrm{Se}-$ ries. The cost of publishing this paper was defrayed in part by the payment of page charges. Under postal regulations, this paper therefore must be hereby marked advertisement solely to indicate this fact. a dimeric enzyme encoded by two loci, the product of one locus being active in the cytoplasm while the other is active in the plastid (Gottlieb, 1981; Weeden and Gottlieb 1979, 1980).

In a previous study, we examined 41 mango cultivars and found two zones of PGI activity, PGI-1 and PGI-2 (Degani et al., 1990). For the cytosolic enzyme, PGI-2, we found two types of banding patterns. We have since examined 139 additional mango cultivars and seedlings and observed four more types of banding patterns for PGI-2. In the present report we describe the various types of PGI2 banding patterns found in mango and pres- 

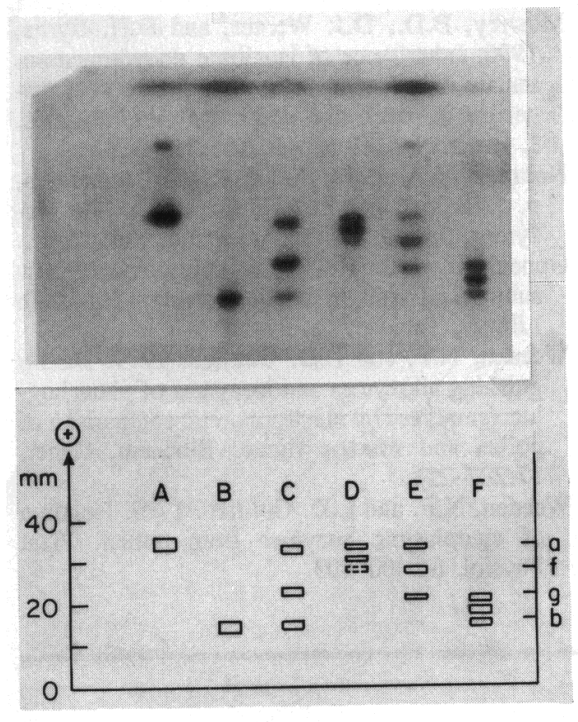

Fig. 1. Electrophoretic patterns of PGI-2 isozyme patterns observed in mango cultivars. Alleles at the Pgi-2 locus are designated a, b, f, and $\mathrm{g}$ (right margin), with their corresponding migration distance (left margin).

Table 1. Progeny segregations and goodness-of fit to 1:2:1 ratio for Pgi-2 genotypes of selfedpollinated mango progenies.

\begin{tabular}{|c|c|c|c|c|c|}
\hline \multirow{2}{*}{$\begin{array}{l}\text { Caged } \\
\text { cultivar }\end{array}$} & \multirow{2}{*}{$\begin{array}{l}\text { Parental } \\
\text { genotype }^{\mathbf{z}}\end{array}$} & \multicolumn{3}{|c|}{$\begin{array}{c}\text { Progeny } \\
\text { segregation }\end{array}$} & \multirow{2}{*}{$\begin{array}{c}x^{2} \\
1: 2: 1\end{array}$} \\
\hline & & aa & $a b$ & $\mathrm{bb}$ & \\
\hline Haden & $a b$ & 4 & 12 & 3 & $1.42^{\mathrm{NS}}$ \\
\hline Irwin & $a b$ & 7 & 13 & 4 & $0.98^{\mathrm{NS}}$ \\
\hline Maya & ab & 14 & 37 & 15 & $0.99^{\mathrm{NS}}$ \\
\hline Zillate & $a b$ & 10 & 20 & 12 & $0.28^{\mathrm{NS}}$ \\
\hline
\end{tabular}

${ }^{\mathrm{z}}$ See Fig. 1 and Degani et al., 1990.

Ns Nonsignificant at $P=0.01$.

Table 2. Phosphoglucose isomerase genotypes (Pgi-2) in mango cultivars.

\begin{tabular}{cl}
\multicolumn{2}{c}{ (Pgi-2) } \\
\hline \hline Pgi-2 & Cultivar \\
\hline ab & Adams, Alphonso, Carrie, Mabroka, \\
& Manzanillo, Momi K, Ostin, Pope, \\
& Radian, Ratna, Ruby, Sandersha, \\
& Suvarnarekha, Vanraj \\
& Badami, Banchot, Dasheri, Gedong, \\
aa & Glenn, Gondoo, Jacquelin, Kavasji \\
& Patel, Kesar, Khas-ul Khas, Langra, \\
& Magshimim, Nam Doc Mai, Nee- \\
& lam, Peach, Pinero, Police, Rupin, \\
& Sefeda, Sensation, Southern Blush, \\
& Zrifin 8 \\
bb & Dabya, Davis-Haden, Golek, Wally \\
af & Bullock's Heart, Mistikawi \\
ag & Faizanson \\
\hline
\end{tabular}

ent their genetic analysis.

Plant material. Leaf samples were taken from mango collections maintained at severa1 places in Israel (Bet Dagan, Rehovot, Zrifin), from chance seedlings from various locations in Israel, and from seedlings selected in several breeding plots. Methods of enzyme extraction from leaves, starch gel electrophoresis, and enzyme staining were described by Degani et al. (1990). For pollen analysis, stamens with closed red anthers were removed from the flowers, placed in petri dishes, and illuminated with a desk lamp un-

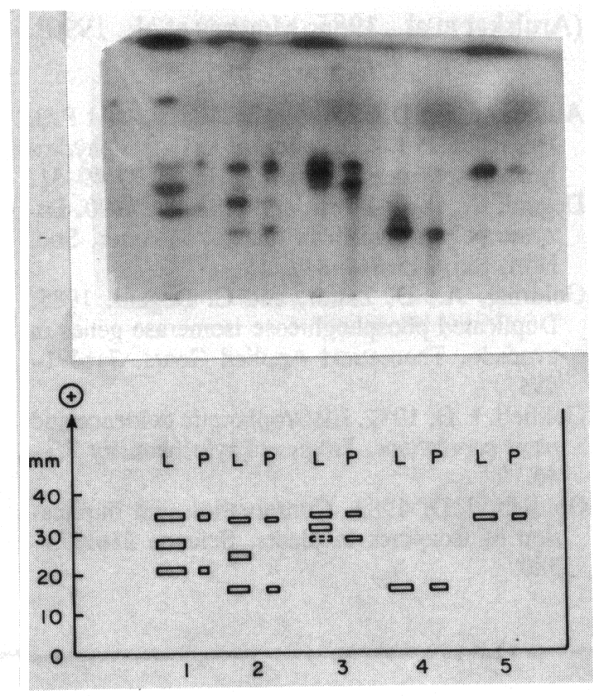

Fig. 2. Electrophoretic patterns of PGI-2 from leaf $(L)$ and pollen $(P)$ extracts of mango cultivars: (1) Faizanson (2) Haden (3) Mistikawi (4) Davis-Haden, and (5) Pairi.

til the pollen sacs opened and the anthers turned gray. After dehiscence, $\approx 30$ stamens were collected and their anthers were immersed for 5 to $10 \mathrm{~min}$ in $0.1 \mathrm{ml}$ of the extraction buffer (Degani et al., 1990). The pollen extracts were absorbed directly onto paper wicks and subjected to horizontal starch electrophoresis. Extracts from the leaf and pollen were compared in adjacent positions on the gel.

Progeny tests. In 1989 single trees of 'Haden', 'Irwin', 'Maya', and 'Zillate' were caged in the Hebrew Univ. experimental orchard at Rehovot before the beginning of flowering, and a beehive was placed within each cage. Progeny fruits were harvested and the mature leaves of their seedlings were subjected to isozyme analysis by the following enzyme systems: aconitase (ACO; EC 4.2.1.3), isocitrate dehydrogenase (IDH; EC 1.1.1.42), leucine aminopeptidase (LAP, EC 3.4.11.1), phosphoglucose isomerase (PGI; EC 5.3.1.9), phosphoglucomutase (PGM, EC 2.7.5.1), and triosephosphate isomerase (TPI; EC 5.3.1.1). The caged trees were located within a large collection of cultivars. The selfed seedlings produced by each cultivar were shown to be a pure selfed population by assaying with enzyme systems for which the caged cultivars are homozygous (Degani et al., 1990). These enzyme systems included: PGM for 'Haden'; ACO, IDH, and PGM for 'Irwin'; ACO, IDH, and TPI for 'Maya'; and ACO, IDH, PGM, and TPI for 'Zillate'. For each caged cultivar, the neighboring cultivars were found to possess different alleles than those of the caged tree, in most, if not all, of the enzyme systems used. Hence, the lack of heterozygous offsprings shows that the seedlings can be considered as pure selfed progenies.

In a previous study, we reported the observation of two PGI-2 phenotypes, a triplebanded, and a single-banded phenotype corresponding to the fast migrant of the triplet phenotype (Degani et al., 1990). The single-banded phenotype corresponding to the slow migrant of the triple-banded phenotype was not found among the 41 cultivars studied. In the present study, the slow one-banded phenotype of PGI-2 has been observed in 12 mango cultivars and seedlings (e.g., 'DavisHaden', 'Wally', 'Dabya', 'Golek').

Additional isozyme phenotypes were detected. Electrophoretic patterns varied for PGI2 isozymes. The homozygous cultivars are of two types, A and B. The heterozygous cultivars fall into four distinct types of banding patterns, C-F (Fig. 1).

Segregation patterns in selfed progeny of four caged cultivars, Haden, Irwin, Maya, and Zillate, all having triple-banded PGI-2 phenotype C (Fig. 1; Degani et al., 1990), were used to elucidate the genetic control of PGI-2 banding patterns. Self-pollinated progeny of these cultivars produced three classes of progeny, including a fast-migrating single-banded phenotype, a triple-banded phenotype, and a slow-migrating singlebanded phenotype, in a 1:2:1 ratio (Table

1). Mendelian inheritance of isozymic banding patterns was tested statistically with $\mathrm{x}^{2}$ tests. The segregation ratios did not differ significantly from Mendelian expectations (Table 1). The fact that the bands occur as singlets and triplets supports the dimeric nature of PGI-2. The allelism of the gene coding for the dimeric enzyme was demonstrated by comparing the electrophoretic patterns of the isozymes in extracts from pollen and leaf (Goldring et al., 1985; Gottlieb, 1982; Weeden and Gottlieb, 1979). In a heterozygous plant, both alleles are present in the diploid tissue and, therefore, a three-banded pattern composed of two homodimeric bands and an intermediate heterodimeric band is displayed. The pollen from the same heterozygous cultivar is a composite of haploid grains, each possessing one of the allelic forms and, therefore, being expected to display only the two homodimeric bands. Indeed, in three types of heterozygous cultivars possessing triple-banded patterns (Fig. 1), i.e., 'Faizanson' (phenotype E), 'Haden' (phenotype C), and 'Mistikawi' (phenotype D), the leaf extracts exhibited the three-banded pattern, while the pollen extracts displayed patterns in which the intermediate band was absent (Fig. 2). The absence of the isozyme with the intermediate mobility in the pollen extracts shows that it is an intralocus hybrid enzyme. Pollen isozyme analysis for phenotype $\mathrm{F}$ could not be carried out since 'Yotvata 85', the only mango cultivar found to possess this phenotype, did not flower. In each of the two types of homozygous cultivars (phenotype A, represented by 'Pairi', and phenotype B, represented by 'Davis-Haden'), both leaf and pollen extracts exhibited the same singlebanded pattern of the respective cultivar (Fig. 2).

The results demonstrate the presence of four alleles, a, b, f, and g, controlling Pgi2 banding (Fig. 1). The Pgi-2 genotypes for patterns A,B,C,D,E, and F are aa bb ab af $\mathrm{ag}$, and gb, respectively. Table 2 presents the Pgi-2 genotypes for a selection of 43 mango cultivars out of the 139 mango cul- 
tivars and seedlings studied in the present work.

Among the total of 180 mango cultivars and seedlings tested thus far (41 earlier and 139 in the present study) 98 possessed the aa genotype, 66 the ab genotype, and 12 the bb genotype. Two polyembryonic cultivars [Bullock's Heart and Mistikawi, both introduced from Egypt (Oppenheimer, 1955)], exhibited the af genotype. Genotype ag is represented by 'Faizanson' and genotype gb by 'Yotvata 85' (a seedling of 'Fajri'). The fact that the alleles $f$ and $g$ are found in very low frequencies may be due to some type of selection pressure against these alleles as previously suggested for malate dehydrogenase alleles present at low frequencies in peach
(Arulskar et al., 1986; Mowrey et al., 1990).

\section{Literature Cited}

Arulsekar, S., D.E. Parfitt, W. Beres, and P.E. Hansche. 1986. Genetics of malate dehydrogenase isozymes in peach. J. Hered. 77:49-51.

Degani, C., R. El-Batsri, and S. Gazit. 1990. Enzyme polymorphism in mango. J. Amer. Soc. Hort. Sci. 115:844-847.

Goldring, A., D. Zamir, and C. Degani. 1985. Duplicated phosphoglucose isomerase genes in avocado. Theoretical Applied Genet. 71:491494.

Gottlieb, L.D. 1981. Electrophoretic evidence and plant populations. Progress Phytochemistry 7:146.

Gottlieb, L.D. 1982. Conservation and duplication of isozymes in plants. Science 216:373380 .
Mowrey, B.D., D.J. Werner, and D.H. Byrne. 1990. Inheritance of isocitrate dehydrogenase, malate dehydrogenase and shikimate dehydrogenase in peach and peach $\mathrm{x}$ almond hybrids. J. Amer. Soc. Hort. Sci. 115:312-319.

Noltman, E.A. 1972. Aldose-ketose isomerases, p. 271-354. In: P.D. Boyer (ed.). The enzymes, 3rd ed. vol. 6, Academic, New York.

Oppenheimer, .C. 1955. The cultivation of new subtropical fruit trees (in Hebrew). Hassadeh Library, Tel Aviv. p. 37-54.

Weeden, N.F. and L.D. Gottlieb. 1979. Distinguishing allozymes and isozymes of phosphoglucoisomerase by electrophoretic comparison of pollen and somatic tissue. Biochem. Genet. 17:287-296.

Weeden, N.F. and L.D. Gottlieb. 1980. Isolation of cytoplasmic enzymes from pollen. Plant Physiol: 66:400-403. 